\title{
Environmental Cooperation in Northeast Asia
}

Jung Wk Kim*

\section{Contents}

I. Introduction

II. Environmental Problems in North-East Asia

1. Air Pollution

2. Marine Pollution

3. Other Environmental Issues

III. Strategies for Environmental Cooperation

1. International Cooperation Proposed at UNCED

2. Strategies for International Cooperation

IV. Conclusions

1. General Status of Infrastructure

2. Transportation Prospects

\section{Introduction}

The world economy is expected to grow tenfold in the coming half century due to mankind's strenuous efforts to improve the standard of living and population growth." But the same processes that are intended to achieve the wellbeing of human beings are threatening the very existence of human being on

* Professor, Graduate School of Environmental Studies, Seoul National University

1) World Commission on Environment and Development, Our Common Future, Oxford University Press, 1987, p. 4. 
this planet. Tenfold economic growth means tenfold production, and tenfold production means tenfold consumption of resources and tenfold environmental destruction, if human beings insist to keep the present way of living. Does the earth have enough resources and environmental capacity to support such economic growth? The answer is "No" in a word.

The world oil reserves are estimated to be about $1.35 \times 10^{12}$ barrels. At the present rate of consumption, the production of oil will reach maximum in the year 2000 and it will be depleted by the year 2050." If the consumption rate increase ten times, the depletion will come much sooner. The coal reserves are estimated to be about $7.6 \times 10^{12}$ tons. At the present rate of consumption, the production of coal will reach its peak in 2100 and it will be depleted by 2500 . $^{3}$

The world economy is sustained by continuously consuming such resources as mineral resources, soil, water, forest, ocean, and others, many of which are not renewable. Even though some of them are renewable, we are consuming them much faster than the renewal rate, so that we are losing forest, soil, other resources at an alarming rate at present.

Environmental problems associated with the consumption of energies and resources impose serious threat also. Global warming resulted mainly from the accumulation of carbon dioxide in the atmosphere, ozone layer depletion caused by the use of CFCs(chloro-fluoro-carbons), desertification from deforestation and ecologically-inadequate development of agricutural lands, and extinction of biological species caused mainly by destroying habitats are the signs of environmental

2) Y. K. Kim et al., Natural Science (Seoul: Saengnung, 1990), pp. $378-380$.

3) Ibid. 
crisis on this planet.

Recognizing such crisis, the United Nations is urging each countries to adopt a new method of development called ESSD(Environmenatally-Sound and Sustainable Development). The main theme of the UNCED(United Nations Conference on Environment and Development) held in Rio de Janeiro in June 1992 was ESSD.

As the environmental problems are globalized, the need for international cooperation to solve them increases also. The Rio Declaration adopted at the UNCED reaffirmed the necessity and urged that every effort should be made by the international community to help states afflicted. The NGOs (non-governmental organizations) are forming international networks also to monitor mankind's common environment and to seek solution to preserve it.

Such international cooperation on environment is urgently needed in the region of North-East Asia. The economic activities in this region are highly concentrated and are expected to grow much further in the coming century. The transport of air pollutants, fresh water and marine pollution, trade of industries, and other environmental problems associated with industrial activities in this region impose serious threats to the wellbeing of peoples in this densely populated region. Therefore, the states in this region should cooperate closely to exchange information, to transfer technology, and to formulate policies to preserve the endangered environment. 


\section{Environmental Problems in North-East Asia}

\section{Air Pollution}

North-East Asia is geographically distinguishable from other parts of the world: Japanese islands to the south separate this region from the Pacific Ocean, Himalaya Mountains and the Pamirs to the west from Western Asia, and Ural and Altay Mountains from Europe.

Westerly wind prevails in this region, so that air pollution in China can be easily transported to Korea and Japan. For example, Yellow Dusts originated from Alashan Desert in Upper Yellow River, Gobi Desert, or Taklamakan Desert are widely observed all over this region. In the Republic of Korea for example, a heavy Yellow Dusts were observed between April 1 and April 10, 1993. Typical wind vectors analyzed during this time showed that north-westerly wind in Mongolia and Northern China could carry air pollution from China to Korea and Japan (see Figures 1 and 2)."

Wind trajectory analysis also showed that dusts from Gobi Desert could be transported to Korea and Japan just in three or four days(see Figures 3 and 4 ).'

In recent years, China shows a remarkable economic growth: the GNP growth rate in 1992 was $12 \%$, which was the world's highest. At that rate China will rise to the economic superpower early next century. ${ }^{6}$ Along with the economic

4) Y. S. Chun, J. M. Shim, C. H. Kim, and B. K. Kim, "Long-Range Transport Model", A Term Paper Report, 1993.

5) D. K. Kang, A Study on the Long-Range Transport of Air Pollutants in North-East Asia, Master Thesis, Graduate School of Environmental Studies, Seoul National University, 1993. 
success, China will produce enormous amount of air pollutants. The amount of $\mathrm{SO}_{2}$ generated in China was estimated to be 16 million tons in 1988 , but it increased to 17.5 million tons in 1990 , which is about twenty times that in the Republic of Korea." The amount of air pollutants generated in this region is expected to reach the world's highest in a near future, which will threaten the air qualities of this region.

The wind pattern in this region is such that air pollution from one state can be carried to any other states within this region. The wind trajectories blowing to Seoul during the period of May 1986 through April 1987 are shown in Figure 5. This figure shows that wind usually blows from Northern China to Seoul during winter seasons and from Southern China and Japan to Seoul during summer seasons. From this result it is possible to infer that air pollutions in highly populated and industrialized areas in Korea, China, and Japan are closely interrelated.

The acid rains are observed even in a remote island called Baiknyung-do, which is located along the West Coast of the Republic of Korea. And it was observed that the acidity of the rains increased with westerly wind, which suggests that the acid rains in this island are affected mainly by the air pollution from China."

6) Time, May 10, 1993, p. 17.

7) T. Y. Kim, A Study on the Effects of Air Pollution in China on the Korean Peninsular, Master Thesis, Graduate School of Environmental Studies, Seoul National University, 1993.

8) Korea Environmental Science Research Committee, A Strategy for Environmental Cooperation in North-East Asia, 1991, pp. 45-48. 


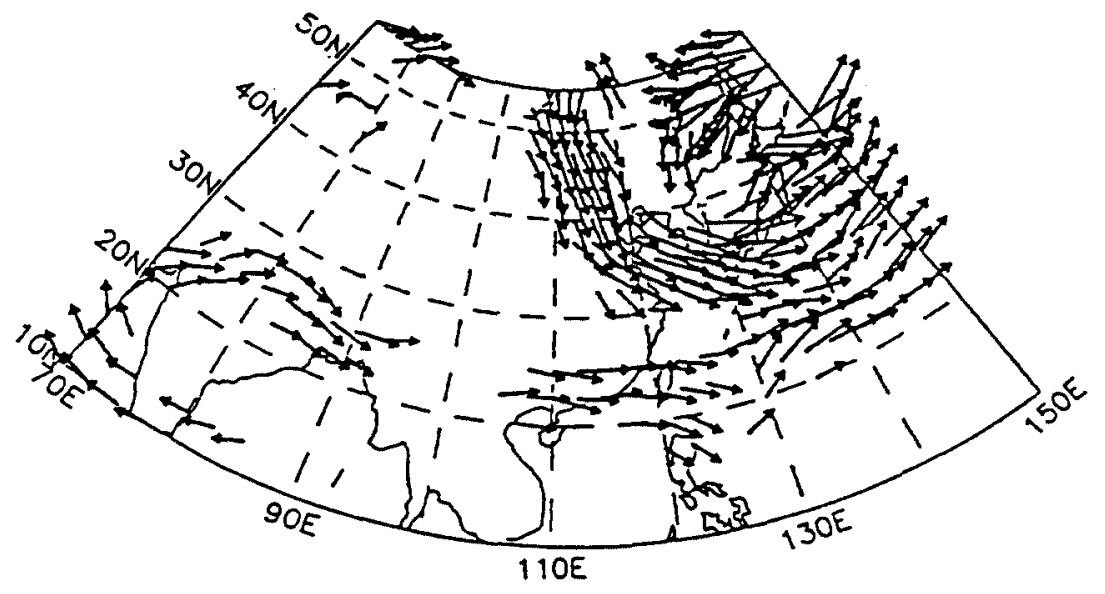

a) at $700 \mathrm{mbar}$

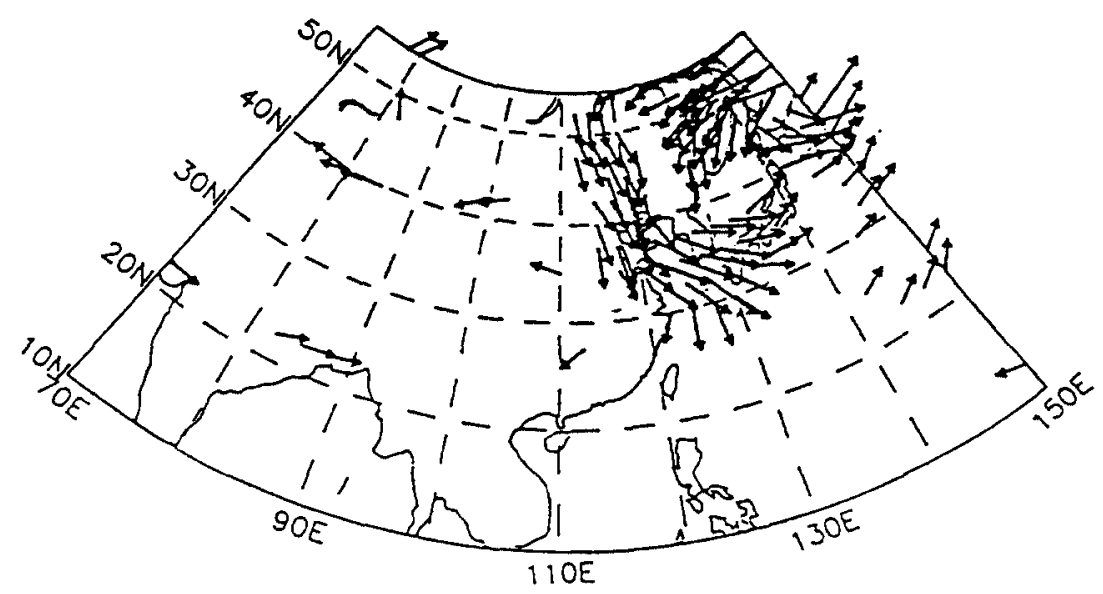

b) at 850 mbar

Figure 1. Wind Vectors in North-East Asia at 00 UTC 7 April 1993

Source: Y. S. Chun, J. M. Shim, C. H. Kim, and B. K. Kim, "Long-Range Transport Model", A Term Paper Report for Air Quality Management Models, 1993) 

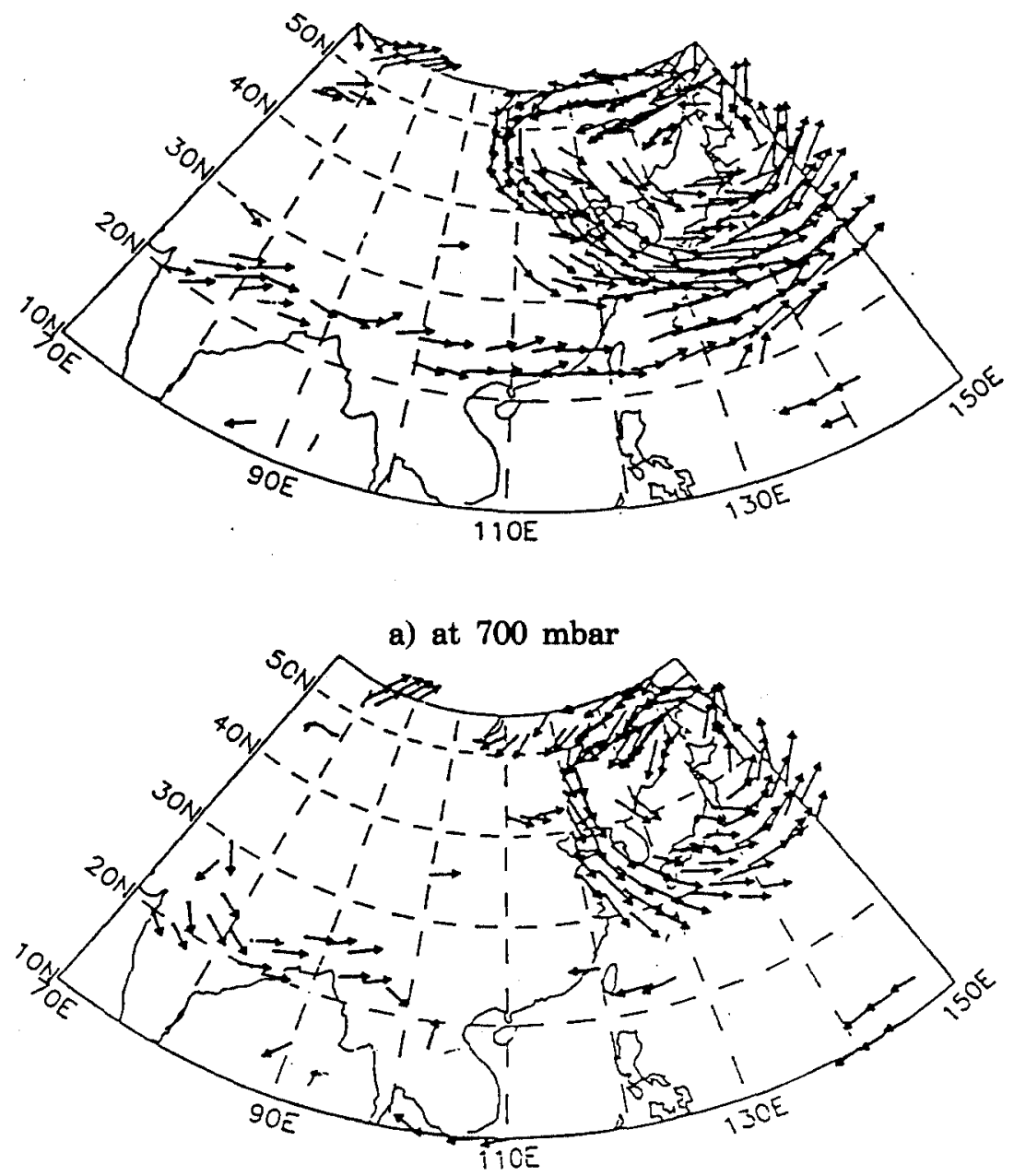

b) at 850 mbar

Figure 2. Wind Vectors in North-East Asia at 00 UTC 8 April 1993

Source: Y. S. Chun, J. M. Shim, C. H. Kim, and B. K. Kim, "Long-Range Transport Modeln, A Term Paper Report for Air Quality Management Models, 1993 


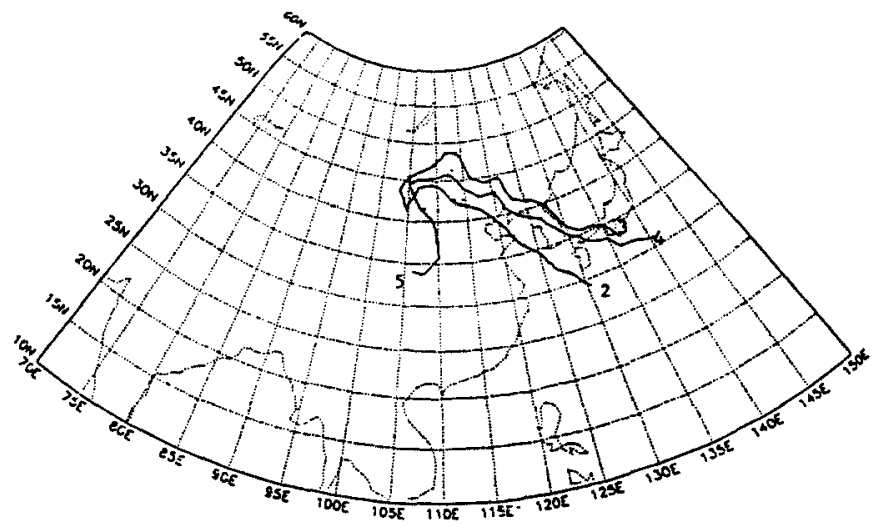

Figure 3. Yellow Dust Trajectories Blowing from Gobi Desert * Lines 2, 3, 4, and 5 mean trajectories at 850 mbar on 2, 3, 4, and 5 April 1993, respectively.

Source: Y. S. Chun, J. M. Shim, C. H. Kim, and B. K. Kim, "Long-Range Transport Model", A Term Paper Report for Air Quality Management Models, 1993.

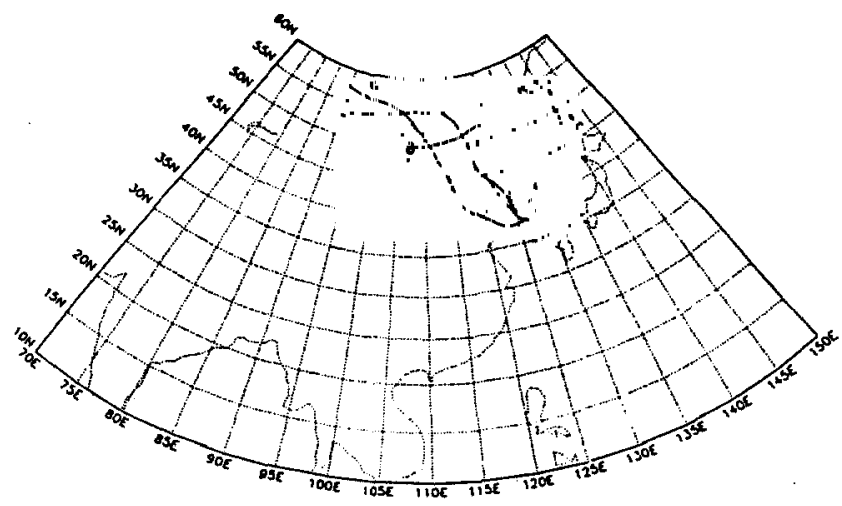

Figure 4. Yellow Dust Trajectories Blowing to Seoul

* Lines 7, 8, and 9 mean trajectories at 850 mbar arriving in Seoul on 7, 8, and 9 April 1993, respectively.

Source: Y. S. Chun, J. M. Shim, C. H. Kim, and B. K. Kim, "Long-Range Transport Model", A Term Paper Report for Air Quality Management Models, 1993. 


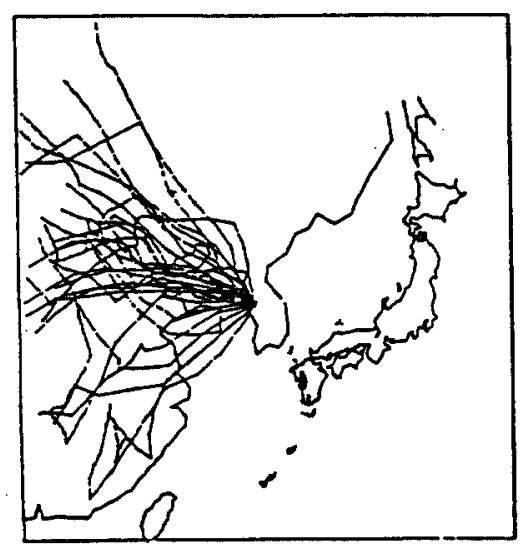

a) January 1987

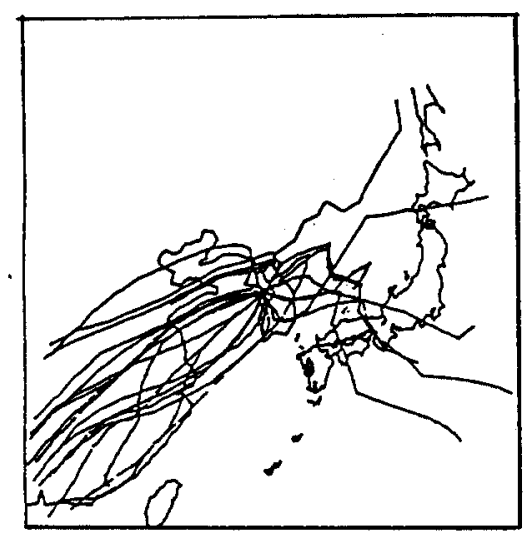

c) July 1986

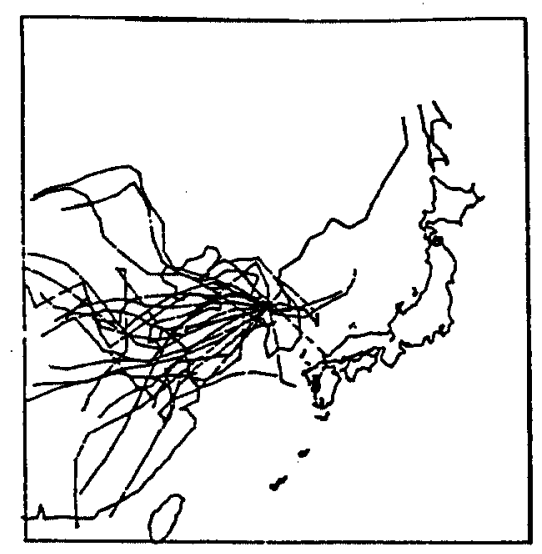

b) April 1987

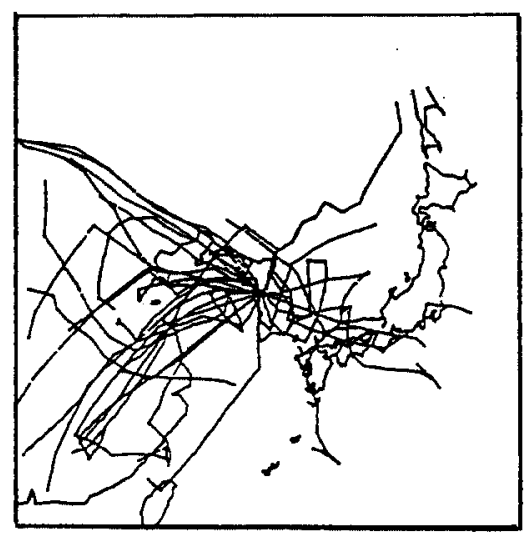

d) October 1986

Figure 5. Backward Trajectories Blowing to Seoul

Source: D. K. Kang, A Study on the Long-Range Transport of Air Pollutants in North-East Asia, Master Thesis, Graduate School of Environmental Studies, Seoul National University, 1993, p. 30) 


\section{Marine Pollution}

The Yellow Sea surrounded by China and Korean Peninsular is a semi-closed sea, the area of which is about 400 thousand square kilometers. It is about 1000 kilometers long from south to north, 700 kilometers wide at maximum from east to west, about 44 meters deep in average, and the maximum depth is 100 meters. Due to the winds in the area, a cold current is formed and proceeds to the south along the Chinese coast, and a warm current comes up to the north along the Korean coast. The exchange between surface waters and bottom waters occurs each year, and mixing within the Sea is very active due to the currents. However, since the Yellow Sea is shallow, small, semi-closed, and relatively stagnant, the capacity to tolerate water pollution is limited.

The major pollution sources in the Yellow Sea are Han River carrying pollution from Seoul City, Yellow River and Yangtze River carrying enormous amount of suspended solids and other pollutants, coastal cities like Tianjin, Dalian, and Chengdu, oil spills from oil search operations and ship wrack, and others.

The Republic of Korea is busy developing the West Coast area to prepare for the 21st. century, presuming that the Yellow Sea would be the center of commerce and industrial activities in the coming century. The 21st. century is often called "West Coast Era" in the Republic of Korea. Large-scale reclamation projects are going on or are planned in most areas along the West Coast. Reclamated lands are either developed as industrial bases or as rice paddies. The removal of mudflats during the reclamation will reduce the pollution-purification ability of the Sea, and the construction of industrial bases will increase the pollution loading to the Sea. 
It seems that China also has ambitious plans to develop huge industrial bases along the coast. The development along the Bohai Bay will have a very serious impact on the environment of the Yellow Sea.

If Korea and China do not take careful precautions in developing coastal areas in the Yellow Sea, the Sea is expected to be seriously polluted in near future.

The Sea of Korea(which is also called Sea of Japan) is encircled by the Korean Peninsular, Russian continent, Sakhalin, and Japanese islands, and has a very limited access to the Pacific Ocean. But, the Sea is not so dangerous as the Yellow Sea, because the Sea is deep and not so stagnant as the Yellow Sea due to ocean currents. However, dumping of wastes in the Sea can affect all states along the Sea because of altercating currents. For example, Koreans and Japanese are deeply concerned over the rumor about the dumping of radioactive wastes in the Sea by the former USSR.

3. Other Environmental Issues

During the process of industrialization the import of technologies and capitals is inevitable especially for developing countries. Formerly, the developed countries used to export pollution-intensive industries to developing countries, possibly because of loose environmental standards in developing countries. The Republic of Korea began industrializing in nineteen-sixties. Many TNCs(transnational corporations) were invited to Ulsan/Onsan Industrial Complexes in the sixties and seventies. Most of those TNCs in the industrial complexes turned out to be pollution-intensive."

Since North-East Asian countries except Japan are newly 
developing countries, it is very likely that pollution-intensive industries will be concentrated in this region because industrialized countries avoid them. TNCs used to adopt double standards, that means strict standards in industrialized countries and loose standards in developing countires. ${ }^{10}$ International organizations including United Nations urge that TNCs adopt globally uniform standards and upgrade pollution control technologies in developing countries. They can do it because they have both technologies and capitals. The economic density in the North-East Asia is expected to be the highest in the world in the next century. Therefore without strict environmental control, it will be impossible to have a decent environment in this region in the next century.

Destruction of habitats is considered as the main reason for the rapid extinction of biological species in the world. The disappearance of wetland, especially tidal wetland, is a special importance in this region regarding the habitats. Tidal mudflats are very productive ecosystems which support marine ecosystems and wetland birds. Ninety per cent of the fishes in the coastal waters are supposed to be linked to the intertidal organisms in the mudflats. Reclamation of wetlands is considered as one of the main reasons for the rapid disappearance of fishes in the Yellow Sea in recent years. And this intertidal organisms in the mudflats are the main food source for waders also. Therefore many migratory birds flock to

9) J. W. Kim, "Environmental Aspects of Transnational Corporation Activities in Pollution-Intensive Industries in the Republic of Korea: A Case Study of the Ulsan/Onsan Industrial Complexes' Environmental Aspects of Transnational Corporation Activities in Selected Asian and Pacific Developing Countries, ESCAP/UNCTC Publication Series B, No. 15, United Nations, N.Y. 276-319 (1990). 10) Ibid. 
these mudflats. Migratory shorebirds in this region spend summers in east Siberia and winters in South-East Asia or even in Australia(see Figure 6). During their migration in springs and falls, the birds stop at wetlands in Korea, China, and Japan for a few days. ${ }^{11}$ The organisms in the mudflats are the energy source for their continuing migration. Therefore the removal of tidal mudflats in these countries is a serious threat to the birds.

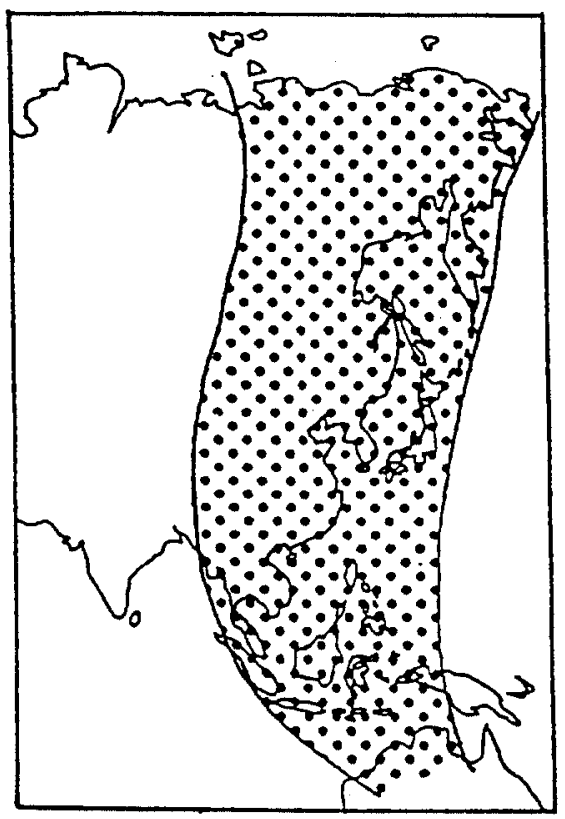

Figure 6. Flyway of East Asian-West Pacific Shorebirds

Source: University of East Anglica and Kyunghee University, A Survey of Coastal Wetlands and Shorebirds in South Korea, Spring 1988, Asian Wetland Bureau, Kuala Lumpur, October 1988, p. 3.

11) University of East Anglica and Kyunghee University, A Survey of Coastal Wetlands and Shorebirds in South Korea, Spring 1988, Asian Wetland Bureau, Kuala Lumpur, October 1988. 


\section{Strategies for Environmental Cooperation}

\section{International Cooperation Proposed at UNCED}

The Rio Declaration, Climate Change Treaty, Biodiversity Treaty, Principles of Forests, and Agenda 21 adopted at the UNCED stress the importance of international cooperation on environment.

Principle 2 of the Rio Declaration says that states have the responsibility to ensure that activities within their jurisdiction do not cause damage to the environment of other states. Principle 9 of the declaration says that states should cooperate to strengthen endogenous-capacity building for sustainable development by improving scientific understanding through exchange of scientific knowledge and transfer of technologies. It is stated in principle 18 that states shall immediately notify other states of any disaster or emergencies that are likely to produce harmful effects on the environment of those states, and that every effort shall be made by the international community to help states so afflicted.

The fundamental for Climate Change Treaty, Biodiversity Treaty, and Priciples of Forests is international cooperation. The same spirit of international cooperation stated in the Rio Declaration is reflected in these treaties.

In article 4 of the Climate Change Treaty, signatories committed to exchange information between all parties and to coordinate with other parties to achieve the objective of the treaty.

In the Biodiversity Treaty, article 14 states "each contracting party shall introduce appropriate procedures requiring environmental impact assessment of its proposed projects that 
are likely to have significant adverse effects on biological diversity with a view to avoiding or minimizing such effects and, where appropriate, allow for public participation in such procedures", and "promote, on the basis of reciprocity, notification, exchange of information and consultation on activities under their jurisdiction or control which are likely to significantly affect adversely the biological diversity of other states or areas beyond the limits of national jurisdiction, by encouraging the conclusion of bilateral, regional or multilateral arrangements, as appropriate". Article 17 of the treaty urges contracting parties to facilitate the exchange of information including results of research, surveying, and others.

In Principles of Forests, principle 15 states "Pollutants, particularly air-borne pollutants, including those responsible for acidic deposition, that are harmful to the health of forest ecosystems at the local, national, regional and global levels should be controlled".

Agenda 21 adopted at the UNCED is a code of action to prepare the world for the environmental challenge of the 21st. century. It also acknowledges that international cooperation should support and supplement national efforts. It specifies what and how to cooperate between governments in detail.

The United Nations acknowledged the importance of NGO activities, and Global Forum, a formal international NGO conference endorsed by the UN, was held in Rio along with the UNCED. Thirty-six alternative treaties were made at the Global Forum. The NGOs touched nearly all subjects associated with environment, including sensitive subjects like militarism, transnational corporations, and nuclear energy which many governments would not like to discuss about. Especially there is a certain treaty called Treaty for NGO Cooperation and 
Sharing of Resources', which was to promote active cooperation and the exchange of information and resources among NGOs locally, nationally and internationally. Fundamentally all NGO treaties are based on international cooperation. International cooperation and exchange of information are more harmonious among NGOs than among governments.

\section{Strategies for International Cooperation}

The scope of international cooperation should include environmental monitoring, exchange of information, transfer of environmental technology, prevention of environmental polluiton from affecting other states, and international joint efforts to recover damaged environment.

International cooperation should not be limited to cooperation between governments. The cooperation between NGOs are very important because NGOs can effectively initiate grassroot movements and monitor if governemnt's environmental policies go wrong. After the Global Forum, NGOs are actively organizing regional and global network to monitor environment and environmental policies and to exchange information and opinions. The international NGO networks are becoming effective pressure groups for governments to enact environmentally-sound and sustainable development policies. There are many environmental issues which need regional cooperation in North-East Asia, but the problem is that it is virtually impossible to contact NGOs in communist countries. These countries had better pay attention to international NGO group meetings and find ways to send delegates to those meetings. From these countries, any environmental experts will be acceptable even though they are not NGO members, as long 
as they do not represent governments.

However, the cooperation between governments is the most powerful tool to solve for the regional environmental problems. In other regions of the world, there have existed various regional treaties or organizations to solve for the regional environmental problems, such as transboundary air pollution, transboundary river basin management, and marine pollution. In North-East Asia, such issues are discussed only in recent years. Between the Republic of Korea and Japan, symposiums have been held three times since 1988 under the objective of promoting environmental cooperation in North-East Asia. And later after the UNCED in 1992, there have been several international sysposiums and conferences also to promote regional cooperation. Governments in the region easily agreed to the necessity of the regional cooperation. But aside that there is not a solid outcome of the meetings yet.

The important environmental issues to be discussed in the regional cooperation are protection of marine pollution, protection of marine biological resources, protection of intertidal wetlands, management of transboundary river basin, protection of wildlife including migratory birds, transboundary atmospheric pollution including acid rain and Yellow Dust, radioactive wastes, trade of wastes, environmental management of transnational corporations, environmental monitoring, exchange of information, transfer of technology, and others.

The marine environments in this region are rapidly deteriorating. Each states related should survey the marine environment under a systematic regional plan and exchange survey data and other scientific informations. Based on the analysis of the synthesized results, future strategies should be discussed between states in the region. In order to carry out 
such missions, existing relevant institutions in each states need to be strengthened and new regional organizations need to be established to synthesize outcomes and monitor marine environment. Paris Treaty and Helsinki Treaty need to be reviewed for reference. Paris Treaty, effectuated in 1974, was aimed to control marine pollution originated from inland. Helsinki Treaty, signed in 1974 but effectuated in 1980, was to protect the environment of the Baltic Sea.

The transboundary atmospheric pollution imposes a serious threat not just on human health temporarily but also on vegetation, soil, and water in long term in wide ranges. The Economic Commission for Europe Convention on Long-range Transboundary Air Pollution in 1979 needs to be reviewed for cooperative programmes for systematic monitoring, assessment, and information exchange. The North America has a similar system to cope with the transboundary air pollution problems. Their experiences will be very helpful in solving the same problem in this region. To assess the nature of long-range atmospheric transport, exchange of scientific knowledge on transport modelling is necessary.

Numerous toxic chemical substances are newly manufactured in recent years, and many countries do have neither accurate information on them nor proper technology to handle them. Therefore industries, especially transnational corporations, need to adopt globally acceptable standards and disclose environmental informations about the toxic chemicals and manufacturing processes of those chemicals. For this purpose international cooperation is compulsary; especially NGOs activities are encouraged because of their unprejudiced attitude on environment. The trade of toxic chemical wastes used to be a serious threat to the environment of developing countries. 
There must be some regional regulations regarding this trade. Principally, trade of toxic wastes should be banned except a few inevitable cases. Dumping of toxic wastes including radioactive wastes in open sea must be closely regulated also. There must be a certain treaty to ban this and a regional organization(or organizations) to monitor it.

\section{Conclusions}

The North-East Asia is one of the most economicallydynamic regions in the world and is still growing very fast probably to become the world's greatest economic center in the next century. Because of high economic density in this region, environmental stresses have built up very rapidly in recent years and it will reach to an unbearable level in the next century. But because of the political situation in this region environmental cooperation among governments used to be insignificant. In order to solve the environmental problems such as transboundary atmospheric pollution, marine pollution, protection of biological resources, and others, international cooperation is compulsary. The international cooperation does not just mean cooperation between governments but also mean cooperation between NGOs. To cope with such environmental problems, regional treaties to regulate inadvertent acts and to encourage international cooperation to solve problems, and organizations to monitor environment and to synthesize strategies are necessary. 